Acta Horticulturae et Regiotecturae 1

Nitra, Slovaca Universitas Agriculturae Nitriae, 2020, pp. 8-11

\title{
THE SAFFRON (CROCUS SATIVUS L.) CULTIVATION INTRODUCTION IN MOUNTAINOUS OASES OF ALGERIA
}

\author{
Khalila BENGOUGA ${ }^{* 1,2}$, Selwa LAHMADI ${ }^{1,2}$, Rouguia ZEGUERROU², \\ Moufida MAAOUI ${ }^{2}$, Youcef HALIS ${ }^{2}$ \\ ${ }^{1}$ Mohamed Khider University, Biskra, Algeria \\ ${ }^{2}$ Center of Scientific and Technical Research on Arid Regions (CRSTRA), Biskra, Algeria
}

\begin{abstract}
An FNR project entitled "Promotion of Saffron (Crocus sativus L.) cultivation for the profit of arid and semi-arid regions' women" is led by the CRSTRA. The investigations made during 2013 and 2014 in different arid and semi-arid regions of Algeria have permitted to install Saffron (Crocus sativus L.) cultivation in five principle sites: Ain Zaatout, Beni Souik, Branis, Djemorah and Maafa (Algeria). These mountainous oases are characterised especially by lack of water. After analysing the investigation results, saffron corms were distributed to women to be cultivated. The sowing was realised on different dates. The results obtained in the first year of saffron cultivation in mountainous oases of Algeria are promising. The flowering took place in the same year in four sites; it is the case of Ain Zaatout, Beni Souik, Djemorah and Maafa. However, the flowering took place in the second year in the site of Branis. The difference in saffron flowering occurrence can be attributed to the difference in altitude, the pedo-climatic difference as well as the difference in the date of sowing.
\end{abstract}

Keywords: Saffron, mountainous oases, flowering, Algeria

Saffron has been a savoured flavour since antiquity, a wellknown and highly priced dried spice which is obtained from the stigmas and the styles' tops of Crocus sativus L. The area of its repartition spreads from the Mediterranean Sea over Persia to India (Ait-Oubahou and El-Otmani, 1999; Schmidt and Betti, 2006). Thus, saffron growing can prosper without doubt in all North Africa; Algeria, Tunisia, and Morocco (Chevalier, 1926). Increasing world interest in the use of fragrance, colour, flavour and medicinal sources with plant origin, has broadened horizon for production and consumption of saffron (Behdani, 2011). It is a traditional production, practiced in Morocco for several centuries (Garcin and Carral, 2007) and it has been operated in Morocco for more than 15 years especially during 2004 (Lage, Faiz and Cantrell, 2006). Nowadays, a pioneering project has been monitored by the CRSTRA during 2009-2012 in Algeria (Lahamadi et al., 2013); the encouraging results of the first project led to the proposition of a second project which was conducted during 2013-2016, focusing on saffron introduction for the profit of rural women. Thus to improve rural population income, and to create and to valorise rural women's jobs; the multi-annual cultivation of saffron not very exigent in surface, water and mechanisation has been introduced in 5 mountainous oases of Algeria.

\section{Material and method}

After a prospection period during 2013-2014 in different arid and semi-arid regions of Biskra and Batna districts
(Algeria: Fig. 1), an enquiry was conducted in five oases about the knowledge and the acceptance of the cultivation of saffron by rural women; samples consisted of $10 \%$ of the families owing land except for the oases of Djemorah where only two samples were inquired due to technical constraints. A woman per household was inquired whether she knew saffron (Crocus sativus L.) and if she accepted to cultivate the corms and keep up the growing until flowering.

Based on the results of the enquiry, 5 sites in the piedmonts of Aurès in North East of Biskra (Fig. 1) were chosen based on their altitudes and acceptance to install saffron (Crocus sativus L.) growing, a mean number of 30 corms (1.5 to $2.5 \mathrm{~cm}$ in diameter) were sown in parcel of $9 \mathrm{~m}^{2}$ in each site (Table 1).

Thus, saffron corms were sown in small areas devoted previously to cultivating subsistence crops. Soil preparation, irrigation and weeding of saffron in experimental parcels are done manually by women who accepted to cultivate saffron. Rainfall annual amount and mean annual temperature during 2014 for the oases of Ain Zaatout, Beni Souik, Djemorah and Maafa and in 2015 for the oases of Branis are mentioned in Table 1, calculated according to www. worldweatheronline.com.

Accordingly, Ain Zaatout known also by the name of Beni Farh, is influenced by the local steppe climate, and throughout the year, there is little rainfall there. However, Beni Souik has a warm Mediterranean climate with dry summers. Branis and Djemorah have a desert climate. In Branis, rain is practically non-existent and in Djemorah

Contact address: Khalila Bengouga, Scientific and Technical Research Center for Arid Regions (CRSTRA) Mohamed Khider University Campus, Biskra, Algeria, tel: +213 778173667; e-mail: leila2000_11@yahoo.fr 


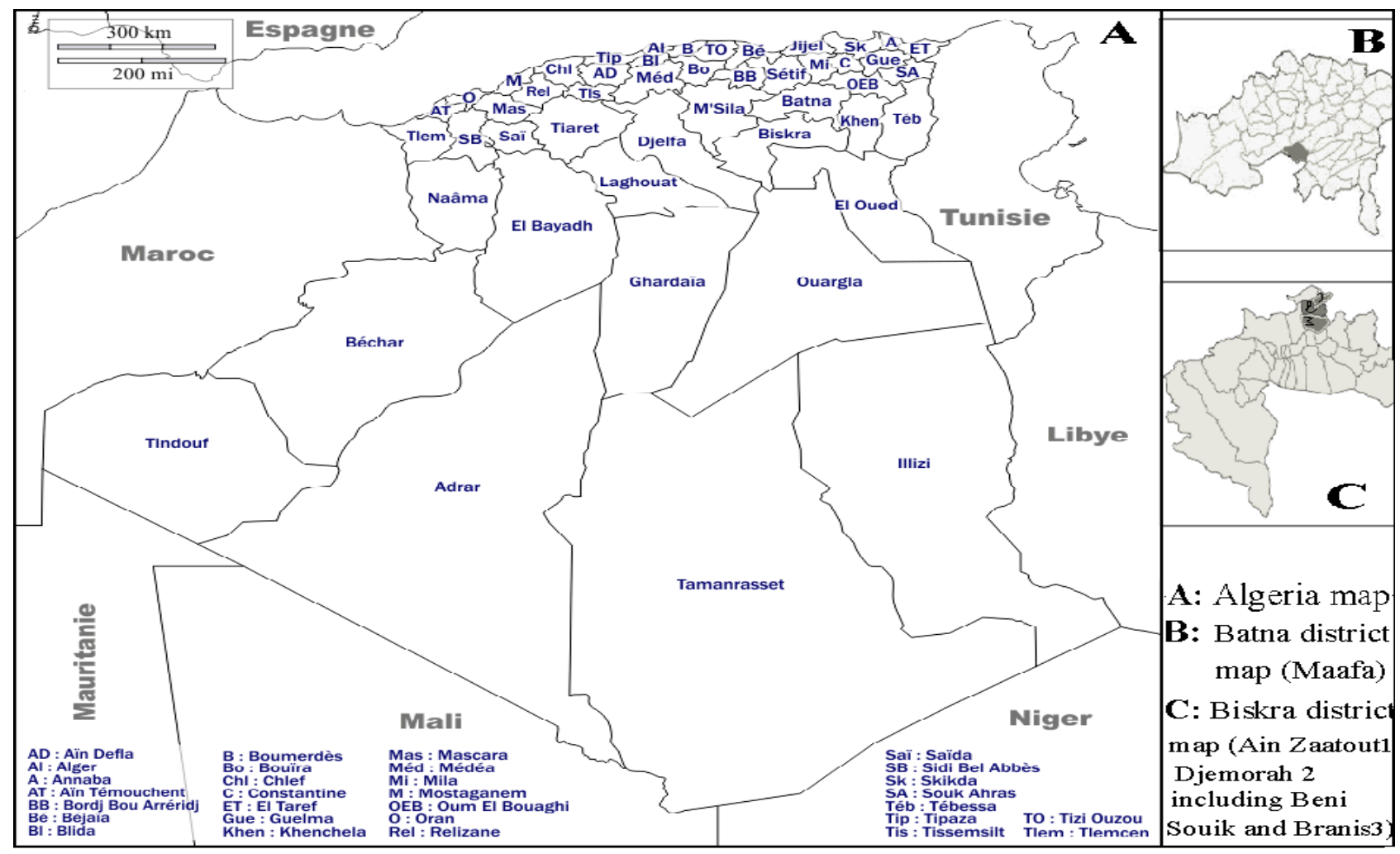

Figure 1 Experimental sites of Crocus sativus L. cultivation

Table 1 Altitude, Rainfall, Mean Annual Temperature and sowing dates of different sites

\begin{tabular}{|l|c|c|c|c|}
\hline Sites & Sowing date & Altitude $(\mathbf{m})$ & Rainfall $(\mathbf{m m})$ & Temperature $\left({ }^{\circ} \mathbf{C}\right)$ \\
\hline Ain Zaatout & $11 / 09 / 2014$ & 831 & 168.53 & 22.58 \\
\hline Beni Souik & $10 / 10 / 2014$ & 553 & 53.46 & 21.83 \\
\hline Branis & $07 / 12 / 2014$ & 250 & 101.2 & 21.83 \\
\hline Djemorah & $09 / 09 / 2014$ & 400 & 53.46 & 21.83 \\
\hline Maafa & $11 / 09 / 2014$ & 735.6 (Tasserghinet) & 263.81 & 15 \\
\hline
\end{tabular}

throughout the year, rain is technically non-existent. Meanwhile, Maafa is influenced by the local steppe climate. The rains are light in Maafa and all year round (climate-data. org and planificateur.a-contresens.net).

\section{Results and discussion}

\section{Enquiry results}

The results in Table 2 show less knowledge of saffron $(27 \%)$ in the prospected regions. The unfamiliarity of the population with saffron, that it is a plant of moderate countries with arid summer (Mediterranean and steppe climate) originated from the Mediterranean seaside where it grows on mountains of low altitude, is probably due to the fact that previously in North Africa, saffron existed only in scarce indigenous gardens (Chevalier, 1926). It has not been operated especially in arid and semi-arid regions and most interrogated women recognised saffron as a spice and not a plant.
The women did not oppose its cultivation. On the contrary, 59\% of them accepted to sow the corms because as rural women of these regions they are interested to improve family income. Especially if they were informed that saffron is the principal source of revenue for the households of mountainous zones in the region of Taliouine-Taznakht in Morocco (Aboudrare, Aw-Hassan and Lybbert, 2014). Also, $55 \%$ of inquired women persist in supporting its cultivation even with the exigency in manual work as rural women were informed that saffron needs 95 days of work (flowers collection, prunage) by household. These tasks have to be realised in October-November. Most of them assumed that they will accomplish the work themselves. Meanwhile, Aboudrare, Aw-Hassan and Lybbert (2014) reported the cut of saffron dried leaves is equally assumed by women. The corms harvest, soil work, sowing, fertilisation and irrigation are essentially masculine tasks. Thus, women answered that they will encourage their family members to contribute in the fulfilment of the growing as it is a family work that needs the involvement of adults as well as young people. 
Table 2 Knowledge and acceptance of Crocus sativus L. cultivation in Algeria (\%)

\begin{tabular}{|l||c|c|c|c|c|c|}
\hline Site & Ain Zaatout & Beni Souik & Maafa & Djemorah & Branis & Total \\
\hline Ni & 24 & 20 & 34 & 2 & 20 & 100 \\
\hline KS & 16 & 10 & 1 & 0 & 0 & 27 \\
\hline AS1 & 10 & 18 & 18 & 2 & 11 & 59 \\
\hline AS 2 & 8 & 18 & 18 & 2 & 9 & 55 \\
\hline
\end{tabular}

$\mathrm{Ni}$ - number of women enquired by site; KS - knowledge of saffron; AS1 - acceptation to cultivate saffron for its important income; AS2 - acceptation to cultivate saffron even with its exigency of manual work

\section{Saffron cultivation}

Saffron presented an adaptation aptitude in sites of an altitude inferior to 600 masl; and it bloomed in the same year in the case of Beni Souik and Djmorah. Flowering dates are staggered in an increasing gradient in the different sites (Table 3): Beni Souik, Ain Zaatout, Djemorah, Maafa and Branis. The length of the period between the date of sowing and flowering (Fig. 2) depends on sowing precocity and tardiness. Sure enough the oasis of Beni Souik has the last date of sowing which is more tardy than those adapted in Morocco (Ait Oubahou and Eloutman, 2002); even though it registered the shortest duration (35 days); this duration is similar to the reports by Skinner, Parker and Ghalehgolabbehbahani (2017) who reported that for the planted saffron corms in mid-late August or early September in watered soil flowering begins after 30-40 days. Meanwhile, all the flowering stages take place during

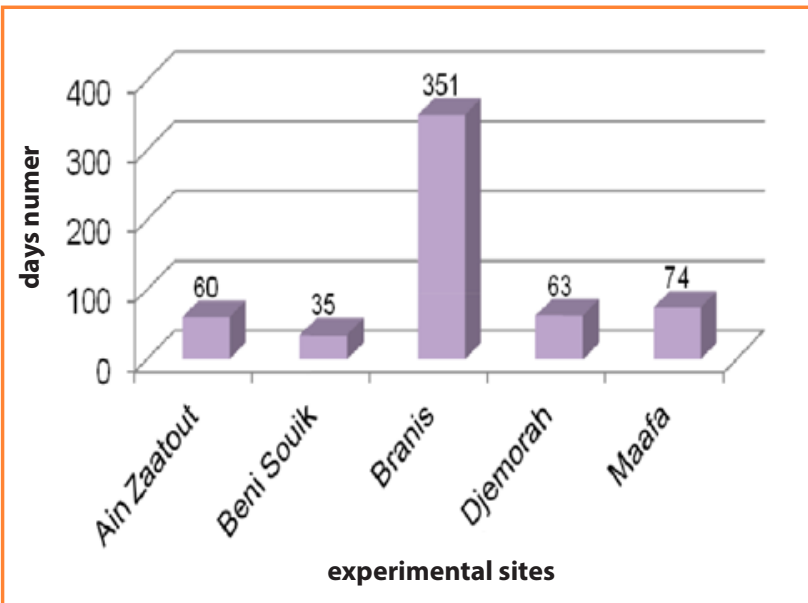

Figure 2 The length of the period between sowing and flowering dates
November; these results are analogous to those reported by Lahmadi et al. (2013) though the authors registered the flowering only during the second year of plantation after a sowing realised on the $3^{\text {rd }}$ October 2010.

Flowering precocity depends especially on altitude and temperature factors, knowing that saffron growing needs altitudes between 600 and $1200 \mathrm{~m}$, and the optimal temperature for flowering of about $17^{\circ} \mathrm{C}$ (Devant, 2008; Molina et al., 2005); thus, the site of Ain Zaatout with the highest altitude $(831 \mathrm{~m})$ presented the most precocious date of flowering. And it is probable that site's saffron that has the best quality as altitude is a determining factor of major metabolites (crocin, picrocrocin and safranal) quality with positive effect particularly on crocins content. (Zarinkamar, Tajik and Soleimanpour, 2011; Lage et al., 2009). However, the sites of Beni Souik and Djemorah presented more precocious flowering dates than the site of Maafa even though this site has a higher altitude; this can be attributed to low temperature registered in the oases of Maafa $\left(11^{\circ} \mathrm{C}\right)$ during November 2014 compared to the two oases of Beni Souik and Djemorah which recorded the suitable mean temperature $\left(17^{\circ} \mathrm{C}\right)$ during November 2014 (worldweatheronline.com). Temperature would be the main criterion for estimating the time of flower emergence in this plant. Flower initiation in saffron starts in the late spring; however, flowers appear in the early autumn (Behdani, 2011). Meanwhile, the site of Branis presented the last date of flowering that is due to tardy sowing of corms in this oasis.

Saffron yield obtained in the five oases (Table 3 ) is low because of the small size of the corms $(1.5$ to $2.5 \mathrm{~cm}$ ) given to rural women to be sown; meanwhile, planting larger-sized corms significantly improved spice yield and daughter corm production in the second year (McGimpsey, Douglas and Wallace, 1997); thus, quality of saffron has not been studied in this year. Nevertheless, we estimate that saffron yield in Ain Zaatout (Beni Farh) is the best one that is attributed to the deep drain soil, rich in organic manure

Table 3 Saffron yields in different sites

\begin{tabular}{|l||c|c|c|c|}
\hline Site & Flowering date & NC & NF & 15 \\
\hline \hline Ain Zaatout & $10 / 11 / 2014$ & 30 & 2 & 50 \\
\hline Beni Souik & $14 / 11 / 2014$ & 30 & 2 & 6.66 \\
\hline Branis & $23 / 11 / 2015$ & 30 & 3 & 6.66 \\
\hline Djemorah & $11 / 11 / 2014$ & 30 & 1 & 10 \\
\hline Maafa & $24 / 11 / 2014$ & 30 & 23 & 3.33 \\
\hline Total & $/$ & 150 & 15.33 \\
\hline
\end{tabular}

$\mathrm{NC}$ - number of corms, NF - number of flowers 
and the satisfactory doses and time of the first irrigation which is the most important factor in initiating the flower emergence in saffron (Behdani, 2011).

\section{Conclusion}

The results obtained in the first year of saffron cultivation in mountainous oases of Algeria are promising. Crocus sativus L. has presented an adaptation aptitude in sites of altitudes inferior to $600 \mathrm{~m}$ (Beni Souik and Djemorah) and a flowering was recorded in the same year of plantation. Indeed, altitude combined with temperature is proved to be a determinant factor of saffron flowering in these sites. As those oases have their special agricultural systems, palm date and arboriculture which must be conserved and since small areas are available to grow up crops, saffron can be introduced as a medicinal plant of high value in association to the ancient agricultural systems to ensure double production of these oases which will increase income of rural population. In order to spread the saffron culture in different Algerian regions, more growers around the country begin to cultivate it; thus, a better appreciation of regional differences effect on saffron life cycle will be obtained to explain the differences of flowering occurrence according to factors such as altitude, temperature, pedo-climatic factors, irrigation and the date of sowing.

\section{References}

ABOUDRARE, A. - AW-HASSAN, A. - LYBBERT T.J. 2014. Importance socio-économique du Safran pour les ménages des zones de montagne de la région de Taliouine-Taznakht au Maroc. In Revue Marocaine des Sciences Agronomiques et Vétérinaires, vol. 2, 2014, no. 1, pp. 5-14.

AIT-OUBAHOU, A. - EL-OTMANI, M. 1999. Saffron Cultivation in Morocco. In Saffron. Ed Harwood academic publishers, 1999, pp. 87-94.

AIT OUBAHOU, A. - ELOUTMAN, M. 2002. Fiche technique la culture du safran. In Bulletin mensuel d'information et de liaison du PNTTA, 2002, no. 91, MADREF/DERD, 4 p.

BEHDANI, M. A. 2011. Saffron (Crocus sativus L.). In Future Crops, 2002, no. 1, pp. 203-208.

DEVANT, I. 2008. La Culture du safran. Fiche technique. Chambre d'Agriculture d'Indre et Loire, 2008, 4 p. https://fr.climate-data.org/afrique/algerie-164/consultedon 19/12/2019 and 22/12/2019

https://planificateur.acontresens.net/afrique/algerie/wilaya de biskra/beni_souk/2504558.html consulted on 21/12/2019

CHEVALIER, A. 1926. La culture du Safran. Revue de botanique appliquée et d'agriculture coloniale, 6e année. In bulletin, 1926, no. 59, pp. 407-419.

GARCIN, D. G. - CARRAL, S. 2007. Le safran marocain entre tradition et marché. Ed FAO 2007, 73 p.

LAGE, M. - FAIZ, C. - CANTRELL, C.L. 2006. Developmental project for introducing saffron (Crocus sativus L.) as an alternative crop in other Moroccan Regions. In Acta horticulturae, 2006, no. 739, pp. 49-52.

LAGE, M. - GABOUN, F. - BAKHY, K. - DAKAK, H. - ZOUAHRI, A. 2009. Sustainable production of high quality saffron (Crocus sativus L.) in some Moroccan areas. In Acta horticulturae, 2009, no. 850, pp. 235-238.

LAHMADI, S. - GUESMIA, H. - ZEGUERROU, R. - MAAOUI, M. BELHAMRA, M. 2013. La culture du safran (Crocus sativus L.) En régions arides et semi-arides cas du sud est algérien. In Journal Algérien des Régions Arides, 2013, no. Spécial, pp. 18-27.

McGIMPSEY, J. A. - DOUGLAS, M. H. - WALLACE, A. R. 1997. Evaluation of saffron (Crocus sativus L.) production in New Zeland. In New Zeland Journal of Crop and Horticulture Science, vol. 25, 1997, no. 2, pp. 159-168.

MOLINA, R.V. - VALERO, M. - NAVARRO, M. - GUARDIOLA, J.L. 2005. Temperature effects on flower formation in saffron (Crocus sativus L.). In Scientia Horticulturae, 2005, no. 103, pp. 361-379.

SCHMIDT, M. - BETTI, G. 2006. Saffron (Crocus sativus): An evaluation of the scientific literature. A joint project; Herbresearch Germany and Medicinal and Aromatic Plants R \& D. Version of May 18, 2006, $17 \mathrm{p}$.

SKINNER, M. - PARKER, B.L. - GHALEHGOLABBEHBAHANI, A. 2017. Saffron Production: Life Cycle of Saffron (Crocus sativus). University of Vermont, North American Center for Saffron Research and Development, 2017, 2 p.

www.worldweatheronline.com: consulted on 24/12/2019

ZARINKAMAR, F. - TAJIK, S. - SOLEIMANPOUR, S. 2011. Effects of altitude on anatomy and concentration of crocin, picrocrocin and safranal in Crocus sativus L. In Australian Journal of Crop Science, vol. 5, 2011, no. 7, pp. 831-838. 